\title{
E-Kitaplarda Tipografik Tasarım Önerileri
}

\author{
Arş. Gör. Zeynep Pehlivan
}

\section{Öz}

Basılı kitapların, yaygınlıklarını hızla e-kitaplara bıraktığı günümüz dünyasında, tipografı çalışmalarının, dijital mecralar için yapılan araştırma ve çalışmaların, e-kitap tasarımları özelinde incelenmesi ve yürütülmesi gerekliliği de giderek artmaktadır. E-kitapların kullandığı temel teknolojiler ve dosya formatları göz önünde bulundurulduğunda sınırlı sayıda tasarım öğesinin tasarımcıların hizmetine sunulduğu görülmektedir. Bu durum, mevcut olan tasarım araçlarının e-kitaplara özgü bir şekilde incelenerek, hangilerinin daha geniş bir tasarım imkanı sunduğunun incelenmesi gerekliliğini getirmiştir.

Anahtar Kelimeler: E-kitap, Tipografik Tasarım Öğeleri, E-kitap Teknolojileri

\section{TYPOGRAPHIC DESIGN SUGGESTIONS FOR E-BOOKS}

\begin{abstract}
As the printed books leave the scene in favor of e-books, the need for typography studies and researches to be inspected and executed specifically on e-books is gradually increasing. Considering the fundamental technologies and file formats used in e-books, it occurs that a limited number of design elements are available under designers' service. Therefore the necessity for analyzing the available design tools specifically for e-books and determining which tools serve for greater design opportunities arises.
\end{abstract}

Keywords: E-book, Typographic Elements, E-book Technologies 


\section{Giriş}

Kitaplar içeriğin depolanmasının yanında paylaşılmasına da imkân sağlayan, telif hakları gözetilerek basılmış medya iletişim araçlarıdır. E-kitap ise fiziksel kitapların dijital kopyası anlamına gelir ve elektronik kitap sözcügünün kısaltmasıdır. Bu terim daha derin bir anlam ile düşünüldüğünde, bir e-kitap geleneksel kitap tanımından daha fazla etkileşim içermektedir. Bu daha fazla hiperlink (hyperlink), yer işareti (bookmark), not alma, kitap üzerinde bir sözlük kullanma ve içeriği bir toplulukla paylaşmak gibi teknolojik yeniliklerin yanında, kitaba her zaman ve her yerden, daha düşük maliyetle ulaşma avantajı da tanır.

Geçen yüzyılın ortalarında, 1950'li yıllarda Johann Gutanberg'in matbaa makinesini icatetmesiyle oldukça büyük bir gelişim gösteren kitap endüstrisi, iletişim ve bilgi teknolojilerine paralel olarak sürekli bir değişim içindedir. Bu değişimin son halkasını kitap endüstrisinde ve yayıncılık sektöründe devrimsel bir nitelik taşıyan elektronik kitaplar oluşturmaktadır (Anameriç ve Rumancl, 2003: 149).

Boş bir sayfa ile kapalı olan bir bilgisayarın ekranının veya tabletin ortak bir noktası vardır. Her ikisi de boş, içerikten yoksun ve olasılıklarla doludur (Gomez, 2008:12). Basılı ortam ile bilgisayar ekranı veya tablet arasındaki göz ardı edilemez benzerliklerin başında ortak kullanım amaçları gelir. Günümüzde giderek yaygınlaşan e-kitaplar da, okuyucular açısından basılı ortam ile dijital platformların kesiştiği önemli bir alandır. 2012 yılı içinde Amerika Birleşik Devletlerinde yapılan kitap satışının \%30'una ulaşmış olan e-kitaplar, son yıllarda \% 70'in altına inmeyen bir büyüme oranı ile kitap pazarındaki ağırlığını her geçen gün artırmaktadır (Businessweek, 2013). Okuyucular ile birlikte, basım ve yayın ile ilgilenen tasarımcıların da hayatına giren e-kitaplar, yeni bir tasarım mecrası oluşturur; ancak tasarımcıların bu yeni mecrada kullanabileceği tipografik tasarım öğeleri, geleneksel basım/yayın organlarındakine göre daha kısıtıdır.

E-kitaplarda tasarım konusunda yapılan araştırmalar, genellikle bir dijital mecra olarak bilgisayarın tercih edildiği araştırmalara odaklanır. E-ink (e-mürekkep) teknolojisi kullanan ilk e-kitap okuyucular, 2006 yılında Sony tarafından, piyasaya sürülmüş; ardından 2007 senesinde pazara giren Amazon Kindle ile yükselişe geçmiş; 2010 senesinde Apple'ın bu alanda yatırım yapması ile bugünkü yaygınlığına kavuşmuştur (Siegel ve Gibbons, 2009). Yaygınlığının bu denli yeni oluşu, e-kitap tasarımı konusunda tipografik incelemelerin de azlığına sebep olmuştur. 
Teknolojiler değişir ve geliştirilirler. Her yeni teknoloji etkileşim içinde olduğu alana yeni ve farklı değerler kazandırır. Ancak üretim ortamları ne kadar değişirse değişsin 'iyi ve 'doğru' üretimler birbirlerine göre elbette farklılıklar taşır. Daha doğrusu her üretim ortamının kendi ölçütleri ve değerleri çerçevesinde 'iyi' ve 'doğru' bir kullanım olgusu vardır. Harfin yaratıı kullanımı bilinçle, estetikle ve duyarlılıkla sağlanır. Ancak tüm bunlar bilgi temelinde oluşur (Sarıkavak, 2009: 1).

E-kitaplar, içerik açısından geleneksel kitaplarla ortak bir çizgide olsalar da, sunum şekli olarak internet siteleri ve bilgisayar üzerindeki dijital platformlar ile benzerlikler gösterirler. Bu benzerliğin temelinde, görüntülenme şekli kadar, teknolojinin tasarım üzerindeki kısıtlamaları da etkilidir. E-kitapların okunduğu platformlar incelendiği zaman, temel olarak iki ana başlıkta değerlendirilebilir: bunlardan birincisi LCD ekrana sahip bilgisayar ve tablet bilgisayarlarken, ikincisi ise basılı kâğıda çok daha yakın bir his sunan e-inkteknolojisine sahip cihazlardır. LCD teknolojisini kullanan cihazlar arasında en çok tercih edilenler; Apple Ipad, Samsung Galaxy Tab, Asus ve Kindle Fire olarak öne çıkarken, e-ink teknolojisinde dünyanın en yaygın kullanımlı cihazı diğer tüm rakiplerinden açık ara önde olan Amazon Kindle olarak öne çıkmaktadır (idc, 2013). E-kitaplardaki tipografik tasarım öğelerinin incelenmesinde, basılı yayın ürünlerinden farklı olarak, teknolojiye bağımlı bir çeşitlilik vardır.

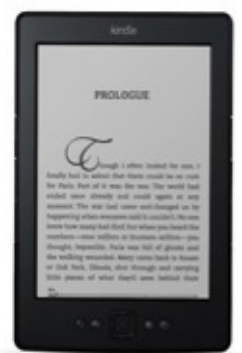

Resim 1: E-ink (Amazon Kindle)

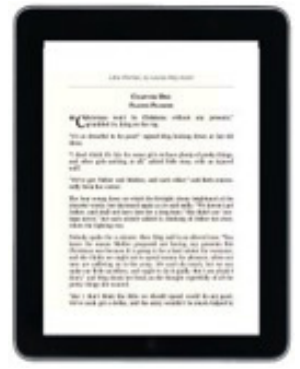

Resim 2: LCD (Apple Ipad)

Bu makalede, tipografik tasarım öğeleri incelenirken gerekli noktalarda her iki teknoloji de ayrı ayrı ele alınmıştır. Temel tasarım öğelerinden hangilerinin tartışılacağı seçilirken, e-kitap teknolojilerinde kullanılamayan tasarım öğeleri göz ardı edilmiştir. Aynı zamanda, PDF ve DOC/DOCX gibi son yıllarda her iki cihaz teknolojisi üzerinde de kullanılabilen; ancak telif hakları açısından net bir çözüm ortaya koyamadığı için e-kitap alanında yaygınlaşamayan ve tercih edilmeyen dosya formatı çözümleri de kapsam dışında tutulmuştur. Makalede öncelikle e-kitaplar için geçerli her bir 
tasarım öğesinin teknoloji bazlı kullanılabilirliği incelenmekte, ardından ön plana çıkan tasarım öğeleri ve tasarım yaklaşımları dikkate sunulmaktadır.

\section{Tipografik Tasarım Öğelerinin E-Kitaplarda Kullanımı}

Basılı bir sayfa, tabletlere oyulmuş yazıların modern bir alegorisidir. Yazı, görseller ve genel tasarım, okuyucudan bağımsız olarak açık ve belirgin olmalıdır; ancak bir elektronik içeriğin okuyucusu, bilgisayar ekranında pencerenin boyutunu veya ekranın çözünürlüğünü değiştirerek ya da tablette yakınlaştırma (zoom-in), uzaklaştırma (zoom-out) yaparak görüntü üzerine etki etme gücüne sahiptir (Massinger, 2011: 5). Okuyucunun görüntü üzerindeki etki etme gücü ve teknolojik kısıtlamalar birleştiğinde, tasarımcının e-kitap için elindeki öğelerin bir kısmı kullanılamamakta, bir kısmı ise sınırlanmaktadır.

Tasarım öğelerinin kullanılabilirliğini incelerken, e-kitap konusunda aktif olarak kullanılan iki teknolojinin de insan gözü tarafından nasıl algılandığını irdelemek, bunu yapabilmek için de, çalışma şekillerinden kısaca bahsedilmesi bir gerekliliktir. E-ink ve LCD görüntü teknolojileri arasındaki en önemlifark, LCD teknolojisinin ışıkyayan diyotlar (led paneller) kullanıyor olması; e-ink teknolojisinde ise elektronik yük ile hareketlenen partiküllerin sabit, mat görseller oluşturmasıdır (electrophoresis teknolojisi). E-ink teknolojisi, led ekrandan farklı olarak kendisi ışık yaymaz. Bu teknolojiyi kullanan cihazlardaki renk algımız bir kâğıttan okumayla aynı şekilde ışığın yansıması ve absorbe edilmesiyle oluşur. E-ink ekranlar sadece görüntüyü değiştirirken enerji kullanırlar (Walk, 2010: 1-4).

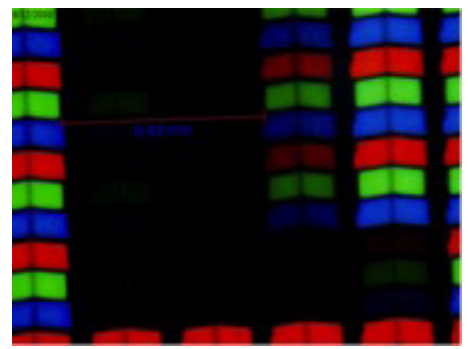

Resim 3: LCD - Ipad (40o kat büyütülmüş)

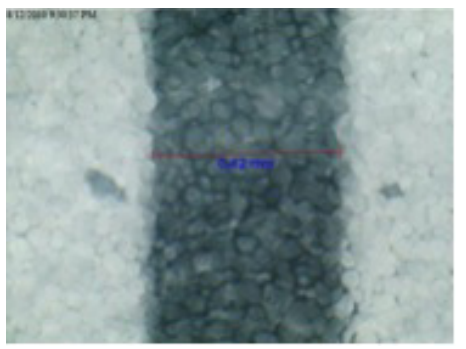

Resim 4: E-ink - Kindle (4oo kat büyütülmüş)

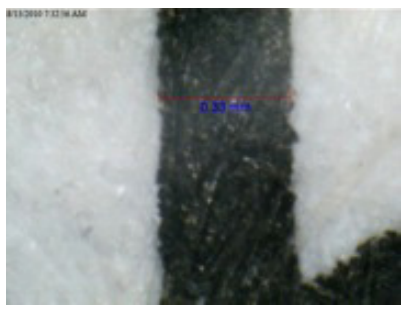


Basılı bir mecra üzerinde tasarım yaparken kullanılan temel tipografik öğelerin bir kısmının e-kitaplar için de kullanılabilen öğeler olduğu görülür. Bunların arasında öne çıkanlar şöyledir:

\section{1- Düzenleme}

Bir metnin planı ve oranları sunulduğu ortamın formatı ile ilişkilidir. Basılı medya ürünleri için ölçüler ve format, hedeflenen görselliğe ulaşmak için tasarımcı tarafından belirlenir. Bu yüzden dengeli bir sayfa yaratmak ve sayfadaki metin alanını belirlemek konusunda birçok yaklaşım mevcuttur. Ancak bu yöntemler klasik bir e-kitap için kullanılamaz. Fiziksel bir kitap için kâğıt ne ise bir e-kitap için ekran çözünürlüğü ve cihazın fiziksel boyutu o'dur. Bu özellikler cihazdan cihaza farklılık gösterdiği için tasarımcı görüntülenecek sayfanın oranlarını düşünmek zorundadır. Birçok e-kitap okuma platformu metin alanının genişliğini ve yüksekliğini kendisi belirler, hatta Kindle gibi bazı cihazlar, her satırda sunulacak kelime sayısını bile kullanıcı tarafından değiştirilebilir hale getirmiştir. Tasarımcı açısından bunun gibi birçok düzenleme ögesinin kısıtlılığına karşın; kutular tanımlayarak belirli metinleri bu kutulara yerleştirmek, metinler için sınırlar tanımlamak, renk değişiklikleri yapmak veya görseller yerleştirmek mümkündür.

\section{2- Yapı}

Bir e-kitabın iskelet yapısı önemli tasarım ögelerinden birisidir. Kapak, konu başlıklarını içeren sayfalar, içindekiler, önsöz, sonsöz, ekler, açıklamalar gibi alanlar kitabın ana bölümü dışında belirtilebilir ve bu alanlar için farklı görsel tasarımlar, farklı tipografik kullanımlar tercih edilebilir. Bu alanlarda iç içe düzende tanımlanmış bir yapı kullanılarak, görsel bir hiyerarşi oluşturulabilir. Bu sayede okuyucunun bir metni taraması, nerede başlayıp bitirebileceğini algılaması ve sunulanlar arasında rahatlıkla bir seçim yapması kolaylaşır (Lupton, 2010: 132). Hiyerarşik olarak en temel öge, okuyucuya metni bölümlendirme şansı veren başlıklardır. Bunun yanı sıra kitabın özünü oluşturan gövde kısmı en fazla dikkati ve titizliği gerektiren bölümdür. Bu alan rahatlıkla okunabilir olmalı ancak okuyucunun dikkatini dağıtmamalıdır (Bringhurst, 2004: 17). Kitabın bölümlerinin birbirinden farklı şekilde tasarlanması ve bu vesileyle tasarımsal bir dili, farklı yansımalarla sunmaları tasarımcılar için etkin bir yöntemdir. E-kitaplarda da tüm temel alanlar ayrı ayrı dosyalar olarak tasarlanarak, birbirinden net bir şekilde ayrıştırılabilmektedir.

Ana alanların yapısal özelliklerine göre daha az etkiye sahip olsa da, sayfa numarası, alıntılar, dipnotlar gibi diğer sayfa ögeleri de gövdeye göre daha az göze çarpması gereken tipografik tasarım noktalarıdır. Örneğin; 
süreli yayınlarda, bu gibi kurallar hedeflenen görsel sonuçları elde etmeye engel olabilir. Böyle bir durumda metnin amaçladığı mesajı vermek için bu kurallar bozulabilir (örneğin alıntılar metnin içerisinden çıkarılarak koyu olarak yazılabilir). Özellikle e-kitaplarda, sayfa öğelerinin sayfa üzerindeki yerleri ve gövde metne oranları sabit kalmadığı için bu öğelerin belirgin bir şekilde ayrıştırılması önemlidir.

\section{3- Yazı Karakteri ve Boyutu}

Tipografi dijital görsellerin en yaratıcı şekilde ödüllendiren bölümlerinden birisidir, ancak aynı zamanda tasarımcıyı en zorlayan bölümlerinden birisi de olabilir. Bazı insanlar karmaşık tipografiye sahip tasarımlar yaparak başarı ile sivrilirken, bazıları acınası bir şekilde olumsuz sonuçlarla karşılaşabilir (Chapman: 7 rules).

Yazı karakteri seçimi yapılırken, konuya olduğu kadar, hedefe de uygun karakterler seçilmelidir (Bringhurst, 2004: 95). Yazı karakteri seçimi; metnin amacl, metnin yapısı, ayraçların ve diğer alfabetik sembollerin kullanımı, metnin yayınlanacağı medya gibi birçok ögenin göz önünde bulundurularak yürütülmesi gereken bir süreçtir. Kitabın gövde bölümünün tamamı genellikle aynı karakterle yazılırken başlıklar, alt başlıklar ve her bölümün ilk harfleri farklı bir ya da iki yazı karakteri içerebilir (Bringhurst, 2004: 95-113).

E-kitaplarda ise yazı karakteri seçimi konusunda sınırlamalar mevcuttur. Bu seçim cihaz tarafından her tür dosyanın rahatça gösterilebilmesi hedefi gözetilerek getirilmiş teknik bir kısıtlamadır. Ancak ipad ve Kindle örneklerinde olduğu gibi, belirli yazı karakteri seçenekleri okuyucuya sunulmaktadır. Farklı mecralar için en okunabilir fontu bulmaya yönelik Subbarams'ın (2004) ve Weisenmillers'ın (1999) çalışmalarına göre, basılı kitap için seçilmiş serifli (tırnaklı) bir yazı karakteri veya LCD ekranlar için özel olarak seçilmiş yazı karakteri, bir E-ink okuyucu ekranı için en uygun tercih olmayabilir (Massinger, 2011: 21).

Sunuldukları platform, e-kitapların tipografik özelliklerini de etkilemekte ve tasarımcı yerine, okuyucunun bu öğeye müdahale etmesine imkan tanımaktadır. Örneğin ipad'de kullanılan i-books e-kitap uygulaması, kullanıcıya 6 adet tırnaklı (serif) ve 1 adet tırnaksız (sans-serif) font seçeneğini, 11 farklı boyut ile görüntüleme imkanı sunarken, e-ink tabanlı Kindle'da ise 3 farklı font 8 farklı boyutta sunulmaktadır.

Varsayılan font ağırlık seçimi konusunda yine aynı ilke geçerlidir. Tasarımcı, sadece okuyucunun kullandığı yazılım desteklediği sürece başlıkların font 
ağırlığını seçme şansına sahiptir (Massinger, 2011: 21).

Okuyucu font büyüklüğü konusunda da istediğini seçme şansına sahiptir. Ancak bu konuda tasarımcının en önemli silahı, farklı ögeler için kullandığı boyutlar arasında birbirlerine oranlarını belirleme şansına sahip olmasıdır. Font büyüklüğü okuyucu tarafından değiştirilse bile, oran sabit kalacaktır.

\section{4- Aralıklar}

Sayfadaki boşlukların dengeli kullanılması gerekliliği yanında, mikro seviyede de harflerin arasındaki boşluklar bir denge sağlamalıdır. Bazı harflerin aralarındaki boşluğun daha fazla olması gerekli iken (örneğin arka arkaya gelen iki kuyruklu harf: gq, gf, qj..) bazı harflerin arasındaki boşlukların da azaltılması (örneğin büyük harften sonra gelen bazı küçük harfler: $T y, A v, V e .$.$) daha okunaklı ve eşit görünmesi için önemlidir$ (Hochuli, 2009: 23-29). Harflerin yakınlıklarının belirlenmesi gövde yazılar için önemli olmakla beraber, başlıkların okunurluğunu artırmak için de çok sık kullanılan bir yöntemdir. Ancak, E-kitaplar için harf aralığı, tasarımcıya bırakılmayan bir öğe olduğu için, tasarımcının, kullanılan cihaz ve yazılımın bu konudaki yaklaşımının dışına çıkma şansı yoktur.

Bir başka önemli aralık ise, satır aralıklarıdır. Bir metnin okunabilirliği yazı tipi, yazı boyutu, harf ve kelime aralıkları ve satır uzunluğu dışında satırların aralıklarından da etkilenir (Hochuli, 2009: 47). Satır aralığı tasarımcının metin bloğunun genel görüntüsünü değiştirmesine olanak veren önemli bir ögedir. Örneğin taban hattı değiştirildiğinde bir metnin grilik değeri de değişecektir. Satır aralığı seçimi, kullanılan karakter seçimi ile ilişkili görünmelidir, anatomik yapısında daha fazla yüksekliğe ve açıklığa sahip olan karakterler daha fazla satır aralığına intiyaç duyarlar. Satır aralığı tasarımcı tarafından değiştirilebilen, önemli bir tasarım öğesi olarak e-kitaplarda her zaman dikkatle ele alınan bir unsurdur. Bu tasarım öğesinin okuyucu tarafından değiştirilmesine olanak tanıyan bazı okuyucu cihazlar olsa da, teknolojiden bağımsız olarak sunulan, yazılımsal bir seçenektir.

\section{5- Vurgulama}

Tipografi konuşmanın kâğıda bir metadil olarak aktarılmış halidir. Konuşurken vücut dili ve tonlama gibi yollarla önem vermek istediğimiz alanları öne çıkartırız. Ancak yazılı anlatımda farklı araçlara intiyaç duyulur. Vurgulama öğeleri, e-kitaplar için de akıcılığı etkileyen önemli faktörlerdir.

\section{a. Noktalama Isşaretleri}

Noktalama işaretleri vurgulamanın en önemli yollarından biridir. Konuşma 
dilini anlattığı için nasıl vurgulama yapılacağı konusunda farklı görüşler vardır. Örneğin alıntı yapılırken tek tırnak ya da çift tırnak kullanılması gibi. E-Kitap'ta genellikle bölgesel olarak basımda kullanılan noktalama işaretleri tercih edilmelidir (Bringhurst, 2004: 86).

\section{b. Yazı Boyutu}

Değişen yazı boyutu, öne çıkarılmak ya da arka plana atılmak istenen bir metnin vurgusunu değiştirmenin bir başka yoludur. E-kitap platformlarında yazı boyutunu belirlemek, tasarımcı yerine okuyucuya verilen bir özgürlük alanı olsa da, yazıların arasında boyut farkı olan bir tasarım yapılarak bu öğe bir tasarım aracı olarak kullanılabilir.

\section{6- Metin Akışı}

Mikrotipografi alanındaki yapısal kontrol; paragraf girişleri, tire ile ayırmalar (tireleme), hizalama, noktalama ve paragraf başlarındaki büyük harfler ile sağlanır. Bunlar ile okumanın akışı desteklenebilir ve arttırılabilir.

\section{7- Formatlar}

Bir e-kitap birden fazla formatta, birkaç dosyadan oluşur. Bu dosyalar kullanılacak e-kitap teknolojisine göre manuel oluşturuluyor olabileceği gibi, tasarımı kolaylaştıran araçlar (yazılımlar) vasıtasıyla da oluşturulabilir. Görünüm üzerinden yapılan, tasarımları e-kitap için gerekli dosyalar, InDesign veya QuarkXPress gibi basılı metin düzenleme araçları ile düzenlenebileceği gibi, WoodWing gibifarklımedya araçları düzenleyebilen yazılımlar ile de yapılabilir.

\section{Sonuç}

Okuyucular için büyük özgürlükler getiren e-kitapların, tipografik tasarım öğeleri açısından sunduğu sınırlandırımış seçeneklere rağmen, tasarımcının tercihine bağlı olarak hayat bulacak birçok öğe vardır. Bu tasarım öğelerinin kullanımı, bir e-kitabın genel estetiğinin yanında, okuyucu açısından kullanım kolaylığını da doğrudan geliştirme şansı sunan önemli bir araçıı. E-kitaplarda bu araçların en öne çıkan yanları; düzenleme, yapı ve yazı boyutudur. Bu durumun, PDF ve DOC/DOCX gibi tüm e-kitap okuyucularının açabildiği formatları göz ardı edilerek varılan bir sonuç olduğu göz önünde bulundurulmalıdır. Bu tür dosyaların e-kitap alanında yaygınlaşması durumunda, basılı yayın için geçerli olan neredeyse tüm tasarım öğelerinin kullanımına olanak sağlanacaktır. E-kitaplar açısından yapılan tipografik çalışmaların azlığı, bu konuda geniş bir literatür bulunmamasına sebep olmaktadır. Bu durum, mevcut olan 
tasarım araçlarının e-kitaplara özgü bir şekilde incelenerek, hangilerinin daha geniş bir tasarım imkânı sunduğunun incelenmesi gerekliliğini getirmiştir. 


\section{Kaynakça}

Anameriç, H. ve Rukancı, F. (2003). E-Kitap Teknolojisi ve Kullanımı. Türk Kütüphaneciliği. Sayı:17 S. 147-166

Bringhurst, R. (2004). The Elements of Typographic Style. 3rd rev. Andexpanded ed. Canada, USA: Hartley \& Marks

Gomez, J. (2008). Print is Dead. Books in Our Digital Age. Londra, UK: Macmillan

Hochuli, J. (2009). Detail in typography. 2nd revised edition. Londra, UK: Hyphen Press

Lupton, E. (2010). Thinking with Type. A critical guide for designers, writers, editors \& students. 2nd rev. And expanded ed. New York: Princeton Architectural Press

Massinger, M. (2011). eBook Typography design \& display of electronic publications for eBook readers and TabletPCs, the St. Pölten University of Applied Sciences

Sarıkavak, N. K. (2009). ÇağdaşTipografinin Temelleri. 2. Baskı. Ankara:SeçkinYayıncılık

Sarıkavak, N. K.(2005). Sayısal Tipogragfi 1. Ankara: Başkent Üniversitesi Yayınları.

Siegel, M. ve Gibbons, F. (2009). Apple Inc. and The E-Book Reader. Stanford University School of Engineering, Case Publisher. 2009-353-1.

Walk, J. (2010). Grundlagen der LED Beleuchtungstechnik.

\section{İnternet Kaynakları}

Internet: Kindle and ipad Displays up close and Personal. (2010). Web:http://www. bit-101.com/blog/?p=2722\%5D adresinden 28.12.2013tarihindealınmıştır.

Internet: Businessweek.As E-Book Sales Rise, Apple iPad Bests Amazon Kindle. (2013).Web: http://www.businessweek.com/articles/2013-01-31/as-e-book-salesrise-apple-ipad-bests-amazon-kindle adresinden 02.01.2014 tarihinde alınmıştır.

Internet: Idc.Web: http://www.idc.com/getdoc.jsp?containerld=prUS24093213 adresinden 28.12.2013 tarihinde alınmıştır.

\section{Görsel Kaynakları}

Resim 1, http://www.gizmag.com/4th-gen-kindle-review/20722/ adresinden 22.12.2013 tarihinde alınmıştır.

Resim 2, http://goodereader.com/blog/good-e-reader-videos/amazon-kindlepaperwhite-vs-the-apple-ipad-with-retina-display adresinden 22.12.2013 tarihinde alınmıştır. 
Resim 3, 4, 5 http://www.bit-101.com/blog/?p=2722\%5D adresinden 25.12.2013 tarihinde alınmıştır. 